\title{
Non heart beating organ donor. New experimental model in pigs ${ }^{1}$
}

\author{
Doador de coração parado. Novo modelo experimental em suínos
}

\author{
Lúcio Kenny Morais ${ }^{\mathrm{I}}$, Pedro Moraes da Silva JúniorI, Juan Carlos Duke Moreno ${ }^{\mathrm{III}}$, Andressa Machado Santana Brasil ${ }^{\mathrm{IV}}$, João \\ Paulo Figueiredo Camarçov, Sarah Barboza Martinsvi, Claudemiro Quireze Júnior ${ }^{\mathrm{VII}}$
}

${ }^{I}$ Fellow Master degree, Program in Health Sciences, UFG, Goiania-GO, Brazil. Responsible for intellectual and scientific content of the study, supervised all phases, provided guidelines for the surgical interventions, manuscript writing.

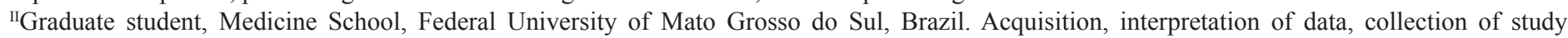
information, manuscript writing.

IIIPhD, Associate Professor, Anesthesiology, EVZ/UFG, Goiania-GO, Brazil. Responsible for intellectual and scientific content of the study, supervised all phases, provided guidelines for the surgical interventions, manuscript writing.

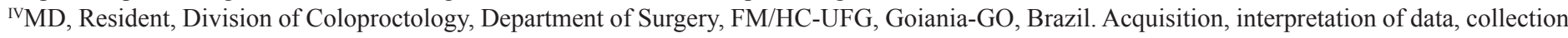
of study information, manuscript writing.

${ }^{v}$ Fellow Master degree, Program in Health Sciences, UFG, Goiania-GO, Brazil. Acquisition, interpretation of data, collection of study information, manuscript writing.

${ }^{\mathrm{V}}$ Fellow Master degree, Program in School of Veterinary and Animal Science, UFG, Goiania-GO, Brazil. Acquisition, interpretation of data, collection of study information, manuscript writing.

VIIPhD, Associate Professor, Surgical Clinics, UFG, Goiania-GO, Brazil. Responsible for intellectual and scientific content of the study, supervised all phases, provided guidelines for the surgical interventions, manuscript writing.

\section{ABSTRACT}

PURPOSE: To describe technical aspects of a new experimental model that simulates a non heart beating organ donor.

METHODS: Landrace pigs were operated on and cardiac arrest was obtained by means of myocardial infarction and interruption of ventilator support.

RESULTS: Mean cardiac frequency, systolic and diastolic blood pressure levels, central venous pressure, oxygen saturation and concentration of expired $\mathrm{CO}_{2}$ dropout occurred at seven minutes after cardiac arrest.

CONCLUSION: The procedure was easily reproduced and a homogeneous circulatory failure could de obtained by the end of seven minutes. The model is suitable for further studies regarding abdominal organ transplantation.

Key words: Transplantation. Models, Animal. Experimental Development. Heart Arrest. Swine.

\section{RESUMO}

OBJETIVO: Descrever os aspectos técnicos de um novo modelo experimental que simula um doador de órgãos após a parada cardíaca. MÉTODOS: Suínos da raça Landrace foram operados e a parada cardíaca foi obtida por meio de infarto do miocárdio e interrupção do suporte ventilatório.

RESULTADOS: Freqüência cardíaca, pressão arterial sistólica e diastólica, pressão venosa central, saturação de oxigênio e concentração parcial de $\mathrm{CO}_{2}$ são consistentes com falência hemodinâmica ao final de sete minutos.

CONCLUSÕES: O procedimento foi facilmente executado e uma falência circulatória pode ser obtida ao final de sete minutos. Este modelo é adequado para estudos posteriores com respeito a preservação e tranplantes de órgãos abdominais.

Descritores: Transplante. Modelos Animais. Desenvolvimento Experimental. Parada Cardíaca. Suínos. 


\section{Introduction}

Liver transplantation is the treatment of choice for terminal liver failure. The most important issue regarding this modality is the gap between an insufficient pool of organ donors and the increasing number of potential recipients ${ }^{1,3}$.

Several alternatives are considered to attenuate this discrepancy, including the use of marginal donors. Therefore, organs from non heart beating donors (NHBD) can be suitable for transplantation, regardless of a worse first year graft survival outcome $e^{1,2,4,9}$. Contemporary aspects of organ donation after cardiac death have stimulated the development of experimental models aiming the improvement of preservation and organ dysfunction ${ }^{2,6,7}$.

There are several methods of simulating a NHBD condition. Interestingly, there is not a standard technique available and the means of promoting the cardiac arrest may contribute to worsen organ preservation ${ }^{2-4,6}$. Thus, new experimental models of non heart beating donating will be useful to control research bias and allow further studies on organ transplantation.

This paper aims the description of a new experimental model of donation after cardiac death.

\section{Methods}

The sample consisted of twelve male Landrace pigs, weighing between 30 and $50 \mathrm{~kg}$, provided by the Poultry Industry (EVZ/UFG). The animals were kept under standard laboratory conditions and fasted for 24 hours before surgery.

This study was approved by the Ethics Committee in Research of the Clinics Hospital Faculty of Medicine Federal University of the Goias (Protocol 042/2011). All procedures were performed at the Laboratory of Experimental Surgery and Anesthesiology, School of Veterinary and Animal Science, Federal University of Goias (EVZ/UFG), according to international principles of animal research and in compliance with Federal Law $\mathrm{N}^{\circ}$. 11.794, of October 8, 2008 and Decree No. 6689 of July 15, 2009 which regulates Law 11794 governing the use of animal experimentation in Brazil. All surgeries were supervised by a veterinarian.

\section{Procedures}

Before general anesthesia, all animals received intramuscular azaperone ( $\left.2 \mathrm{mg} \cdot \mathrm{kg}^{-1}\right)$. After 10 minutes, animal received intramuscular ketamine $\left(10 \mathrm{mg} . \mathrm{kg}^{-1}\right)$, midazolam $(0.5$ mg. $\left.\mathrm{kg}^{-1}\right)$ and meperidine (4 mg. $\left.\mathrm{kg}^{-1}\right)$. The marginal ear vein was catheterized and anesthesia was induced with iv propofol (5-10 mg. $\left.\mathrm{kg}^{-1}\right)$. The internal carotid artery and both jugular veins were dissected and isolated. Lines were placed for for blood pressure measurement, blood sampling and fluids administration (Figure $1)$.

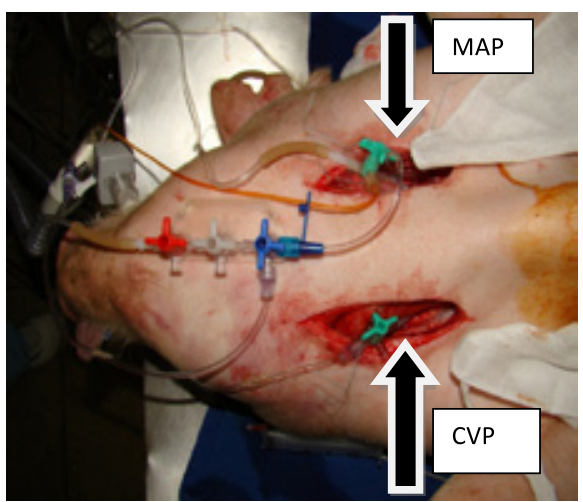

FIGURE 1 - Instrumentation of swine by dissection and catheterization of the jugular veins and both internal and external carotid arteries. MAP Mean Arterial Pressure; CVP - Central Venous Pressure.

General anesthesia was maintained with isoflurane and continuous infusion of fentanyl $\left(10 \mu \mathrm{g} \cdot \mathrm{Kg}^{-1}\right)$ and atracurium (0.4 mg. $\mathrm{kg}^{-1} /$ hour). We performed intermittent positive pressure ventilation to maintain normocapnia $(35-45 \mathrm{mmHg})$.

\section{Surgical protocol}

The surgical approach was performed by wide median thoracoabdominal incision (Figure 2). Heparin (500 IU-kg) was administered in bolus five minutes before cardioplegia. Cardiac arrest was obtained by en block suture of both coronary arteries and interruption of ventilatory support (Figures $3 \mathrm{~A}$ and B). Absence of arterial pulse wave and the presence of either fine ventricular fibrillation or isoelectric line were the criteria to consider the animal as a donor after cardiac death. At this point, euthanasia was obtained by means of exsanguination under general anesthesia. The carcasses were properly incinerated, at the Department of Pathology (EVZ/UFG).

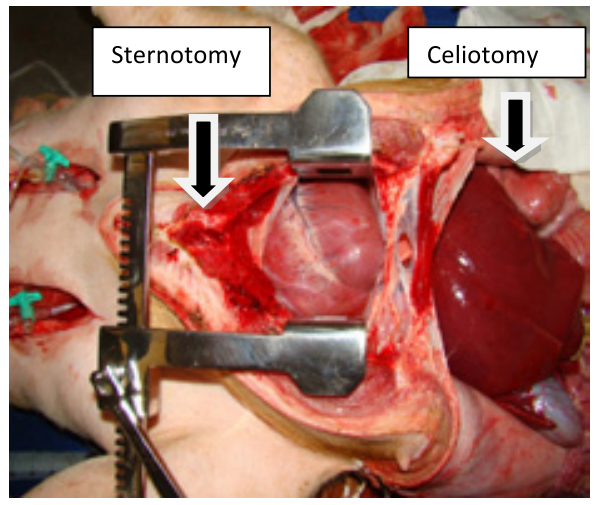

FIGURE 2 - Thoracoabdominal surgical approach. 

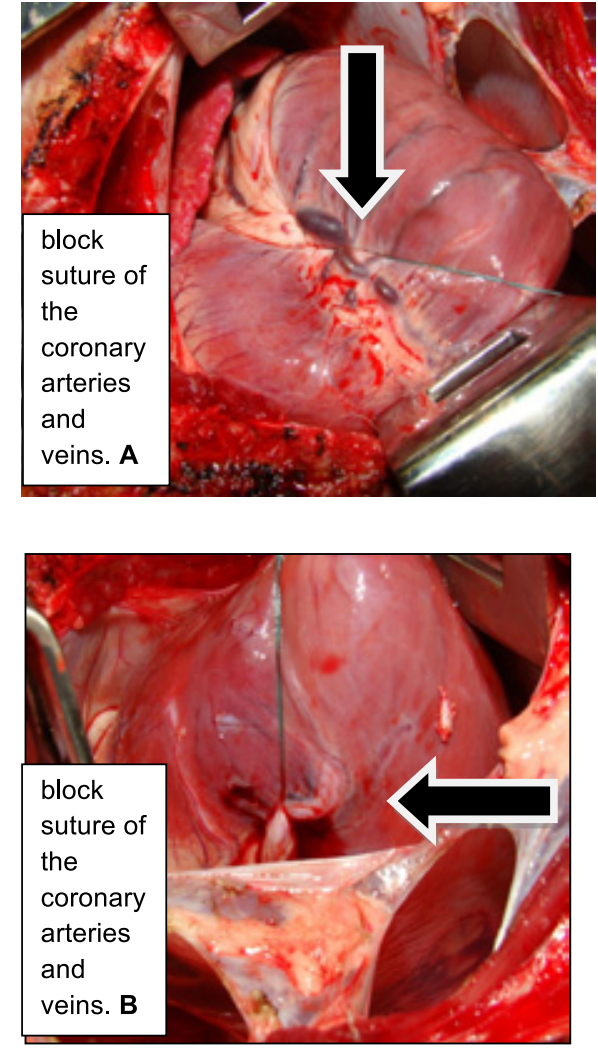

FIGURE 3 - Method of cardioplegia block suture of the coronary arteries and veins before (A) and after (B).

The studied variables included heart rate, systolic, mean and diastolic blood pressure, central venous pressure, pulse oximetry and $\mathrm{CO}_{2}$ concentration at the end of expiration throughout the surgical procedure.

\section{Statistical analyses}

Data were expressed as mean values, reporting hemodynamic and gasometrical parameters during the surgical procedures.

\section{Results}

Concentration of expired $\mathrm{CO} 2$ remained near $50 \mathrm{mmHg}$ during the first three minutes after cardiac infarction. An abrupt increase was noticed after this point, reaching $75 \mathrm{mmHg}$ by the end of seven minutes (Figure 4).

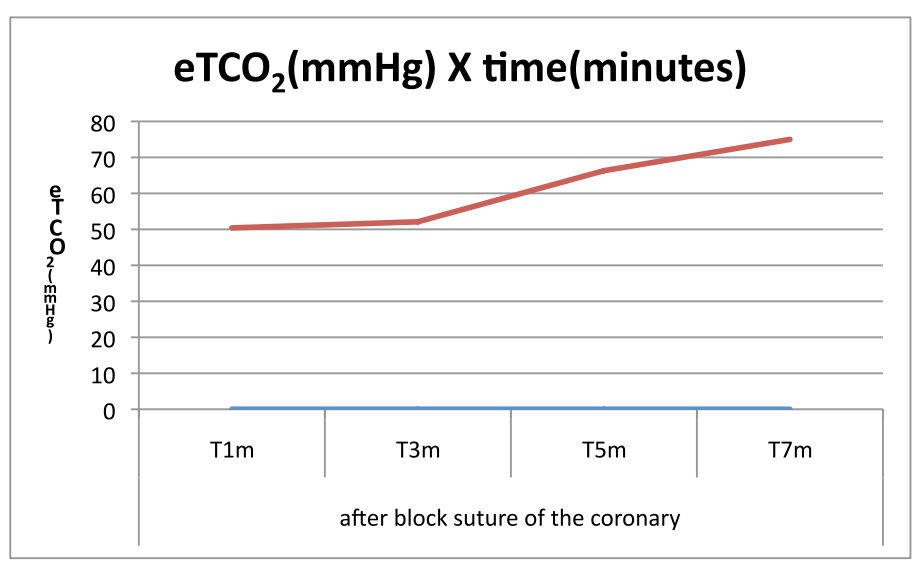

FIGURE 4 - The concentration of $\mathrm{CO}_{2}$ in expired gas in relation to time in minutes.

Mean cardiac frequency of 250 beats per minute (bpm) came to a near $140 \mathrm{bpm}$ after three minutes of cardiac infarction and was undetectable by the end of seven minutes (Figure 5).

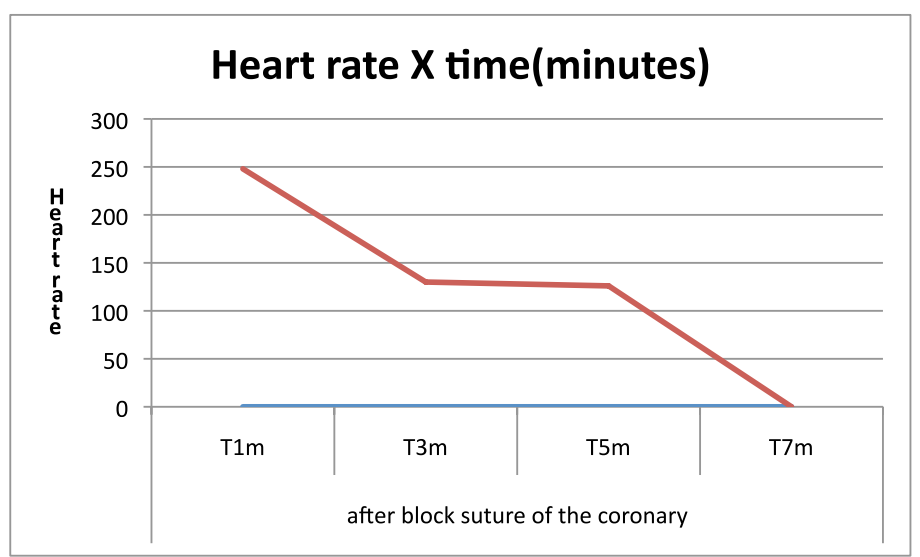

FIGURE5 - The heart rate versus time in minutes.

Systolic and diastolic blood pressure levels showed a drop from $75 \times 26 \mathrm{mmHg}$ to $65 \times 22 \mathrm{mmHg}$ (mean: $40 \mathrm{mmHg}$ ) during the initial three minutes of surgical protocol. Both blood pressure levels were undetectable by the end of seven minutes (Figures 6 to 8 ).

\section{Sistolic arterial pressure-SAP $(\mathrm{mmHg})$ $X$ time(minutes)}

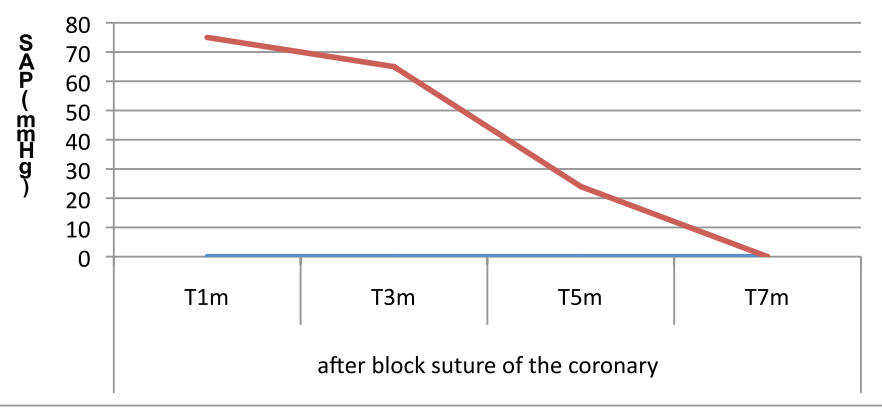

FIGURE 6 - The systolic arterial pressure to time in minutes. 


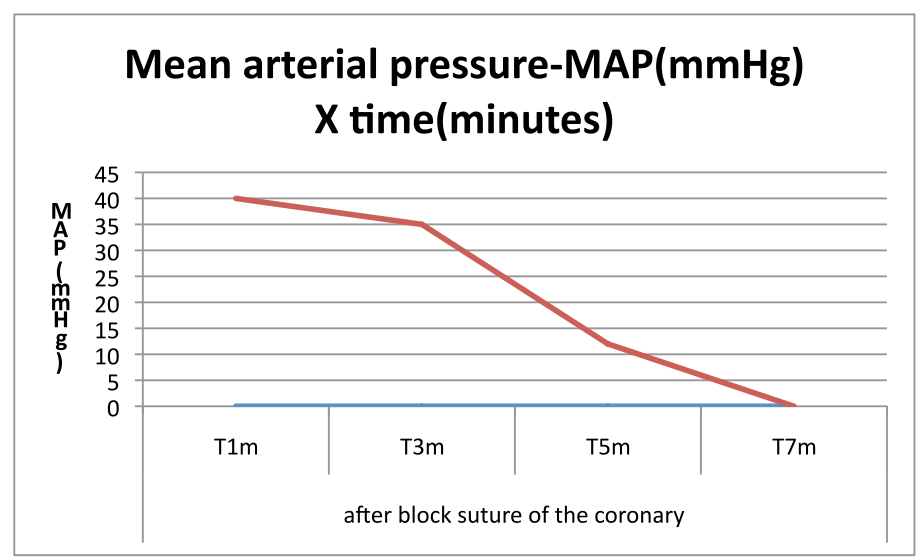

FIGURE 7 - The mean arterial pressure to time in minutes.

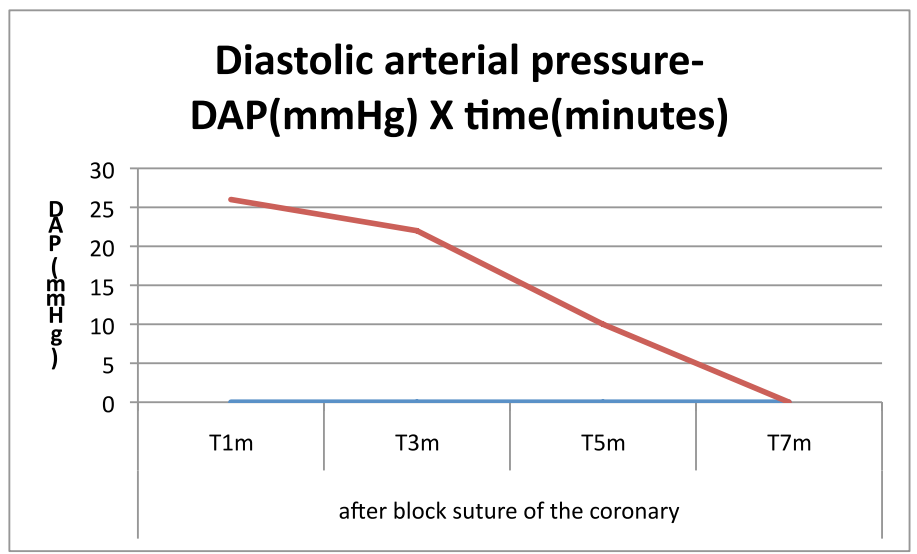

FIGURE 8 - The diastolic arterial pressure to time in minutes.

Oxygen saturation remained near 100\% during the first five minutes, and undetectable by the end of seven minutes of the experimental protocol (Figure 9).

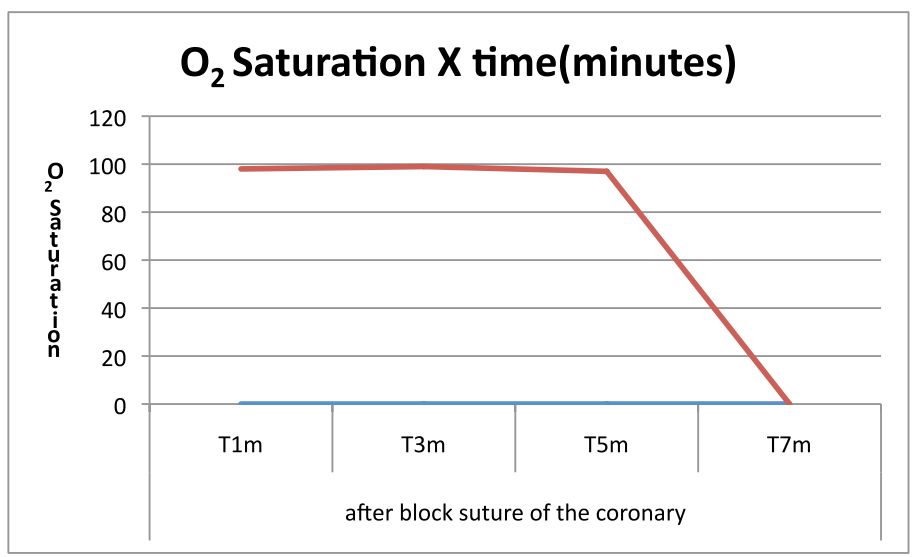

FIGURE 9 - The $\mathrm{O}_{2}$ saturation to time in minutes.

Central venous pressure levels showed an increase from $2 \mathrm{mmHg}$ to $11 \mathrm{mmHg}$ by the end of seven minutes (Figure 10).

\section{Central venous pressure $(\mathrm{mmHg}) \mathrm{X}$ time(minutes)}

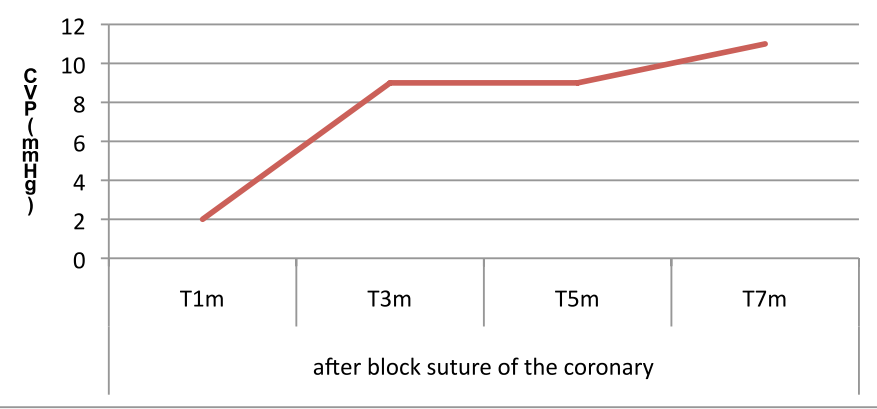

FIGURE 10 - The central venous pressure to time in minutes.

\section{Discussion}

This paper presents a new experimental method suitable for studies on organ donation after cardiac death. Our results have shown that the surgical protocol is easily performed and a homogenous circulatory collapse can be obtained by the end of seven minutes. Since no pharmacologic agents were used with the intent of cardiac arrest, we speculate that organ preservation can be achieved with minimal experimental bias. We also believe that the reproducibility of the method may be useful to the rational use of animals in studies of non heart beating organ donation. Economic savings might be another benefit to consider, as well as the usefulness of the method on simulating the Maastricht's category III of $\mathrm{NHBD}^{2,10}$.

Sato et al. ${ }^{15}$ presented a study in which cardiorespiratory support was removed to obtain the model of cardiac arrest. The criticisms of this model are the absence of specification of electrocardiographic criteria used to define heart failure and high variability of time between the withdrawal of support and cardiac arrest, which interferes with normothermic ischemia and potentially compromises the analysis of variables and outcomes.

Schön et al. ${ }^{14}$ describe the exsanguination as a way to obtain the donor heart arrest. The induction of hypovolemic shock in this model directly interferes in the organ to be preserved, since hypovolemia worsens and begins the process of ischemia and reperfusion, making it difficult to validate the proposed results.

Takada et al. ${ }^{11}$, Kamachi et al. ${ }^{12}$ and Valero et al. ${ }^{13}$ are groups that describe the model by administering a lethal dose of potassium chloride. However, there is significant interference to the mechanism of active transport across membranes by $\mathrm{K}+/ \mathrm{Na}+$, promote cellular changes that can compromise organ preservation.

Our surgical protocol, on the other hand, focuses on the avoidance of strategies that could jeopardize organ preservation 
and is currently being used in our laboratory for studies on liver and kidney transplantation.

\section{Conclusions}

The method is technically simple and a reproducible circulatory arrest can be obtained by the end of seven minutes. This model is suitable for further studies regarding abdominal organ transplantation.

\section{References}

1. Chan EY, Oison LC, Kisthard JA, Perkins JD, Bakthavatsalam R, Halldorson JB, Reyes JD, Larson AM, Levy AE. Ischemic cholangiopathy following liver transplantation from donation after cardiac death donors. Liver Transpl. 2008;14(5):604-10.

2. Monbaliu D, Crabblé T, Roskams T, Fevery J, Verwaest C, Pirenne J. Livers from non-heart-beating donors tolerate short periods of warm ischemia. Transplantation. 2005;79(9):1226-30.

3. Cassavilla A, Ramirez C, Shapiro R. Experience with liver and kidney allografts from non-heart-beating donors. Transplantation. 1995;59:197-10.

4. D'Alessandro AM, Hoffmann RM, Knechtle SJ. Controlled nonheart-beating donors: a potential source of extrarenal organs. Transplant Proc. 1995;27:707-21.

5. Tojimbara T, Kennedy RG, Burns W. The use of non-heartbeating cadaver donors in experimental liver transplantation. Transplantation. 1995;60:1179-92.

6. Quintela J, Gala B, Baamonde I. Long-term results for liver transplantation from non-heart-beating donors maintained with chest and abdominal compression-decompression. Transplant Proc. 2005;37:3857-8.

7. Reddy S, Greenwood J, Maniakin N. Non-heart-beating donor porcine livers: the adverse effect of cooling. Liver Transpl. 2005; 11:35-8.

8. Bernat JL, D'Alessandro AM, Port FK. Report of a national conference on donation after cardiac death. Am J Transplant. 2006;6:281-91.

9. Alvarez J, del Barrio R, Arias J. Non-heart-beating donors from the streets: an increasing donor pool source. Transplantation. 2000;70:314-7.

10. Otero A, Gomez-Gutierrez M, Suarez F. Liver transplantation from Maastricht category 2 non-heart-beating donors: a source to increase the donor pool? Transplant Proc. 2004;36:747-50.

11. Takada Y,Taniguchi H, Fukunaga K. Hepatic allograft procurement from non-heart-beating donors. Limits of Warm ischemia in porcine liver transplantation. Transplantation. 1997;63:369-83.

12. Kamachi H, Nakajima Y, Kimura J. Study of Liver function in a graft suffering from warm ischemia in porcine liver transplantation. Transplant Proc. 1996;28:1789-91.

13. Valero R, Garcia-Valdecasas JC, Tabet J. Hepatic blood flow and oxygen extraction ratio during normothermic recirculation and total body cooling as viability predictors in non-heart-beating donor pigs. Transplantation. 1998;66:170-82.

14. Schön MR, Kollmar O, Wolf S. Liver transplantation after organ preservation with normothermic extracorporeal perfusion. Ann Surg. 2001;233:114-26.

15. Sato M, Ohkohchi N, Tsukamoto S. Successful liver transplantation form agonal non-heart-beating donor in pig. Transpl Int. $2003 ; 16: 100-8$.

\section{Correspondence:}

Prof.Dr. Claudemiro Quireze Júnior

UFG - Faculdade de Medicina -

Divisão de Cirurgia Digestiva - Departamento de Cirurgia

Rua 7, 247/902 Setor Oeste

74110-090 Goiânia - GO Brasil

Tel.: (55 62)3269-8204

cquirezejr@gmail.com

Received: December 20, 2011

Review: February 21, 2012

Accepted: March 19, 2012

Conflict of interest: none

Financial source: none

${ }^{1}$ Research performed at Laboratory of Experimental Surgery and Anesthesiology, School of Veterinary and Animal Science, Federal University of Goias (EVZ/UFG), Goiania-GO, Brazil. Part of the thesis Master degree in the Postgraduate Program in Health Sciences. 